\title{
Considering Coherence: Teacher Perceptions of the Competing Agendas of RTI and an Existing Special Education Model
}

\author{
Angela Pyle \\ Queen's University
}

\begin{abstract}
In 2005, the Ontario Ministry of Education introduced Responsiveness to Intervention (RTI) to the Ontario school system. RTI is a tiered approach involving increasing levels of support for students who are at risk for later learning difficulties. However, the introduction of this different support structure was not accompanied by a substantial shift in Ontario's process of identifying and supporting struggling students. This paper uses focus group data to describe the perspectives of teachers who participated in the implementation of RTI and the tensions they experienced due to the lack of coherence between RTI and a special education framework where psycho-educational testing is the gateway to additional support.
\end{abstract}

Supporting students who experience learning difficulties has long been discussed by teachers and researchers alike. Responsiveness to Intervention (RTI) is a recently developed model intended to improve the learning of students at risk for later learning difficulties by providing the opportunity to identify and intervene earlier in their academic careers. This model advocates the use of intervention as a step in the identification of students who are at risk, which involves closely monitoring students in the primary years and providing additional support through direct instruction. In 2005, Ontario's Expert Panel on Literacy and Numeracy Instruction for Students With Special Education Needs included RTI in their report titled Education for All. The purpose of this report was "to recommend practices, based on research, that would allow Ontario's teachers to improve and reinforce effective instruction of reading, writing, and mathematics to students from Kindergarten to Grade 6 who have special education needs" (Ontario Ministry of Education [OME], 2005, p. 1). In this document, the panel introduced a model based on RTI research termed the tiered approach. This was the first - and at the time of this study, the only-formal introduction of RTI into the Ontario education system.

RTI advocates the support of struggling learners by providing intervention as a step in the process of identification. In the extant research, this support has primarily been implemented with struggling readers and there are numerous empirical studies reporting the potential benefits 
of RTI for these students (e.g., Feiker Hollenbeck, 2007; Fuchs \& Deshler, 2007). Based on this research and the recommendation put forth in Education For All (OME, 2005), some school boards in Ontario have begun to implement RTI in their classrooms (Mattatall, 2011; Pyle, in press). This begs the question, is Ontario ready for RTI? To begin to answer this question, this study sought to explore the perspectives of teachers who participated in an RTI pilot project in one of these school boards.

Research in the United States, where RTI has been legislated for use since 2004, shows that implementation of RTI requires a substantial change in how teachers work with struggling students (Denton, Vaughn, \& Fletcher, 2003) and yet, this same research rarely considers the perspectives of educators working within this model (Greenfield, Rinaldi, Proctor, \& Cardarelli, 2010). Thus, this paper will describe the experiences of teachers during a yearlong pilot project. The findings from this research point to the barriers presented by a lack of coherence between RTI and the existing special education framework mandated in Ontario (OME, 2001).

\section{Responsiveness to Intervention (RTI)}

RTI is a three-tiered model involving increasing levels of intervention for students who are at risk for later learning difficulties (e.g., Fuchs \& Fuchs, 2007). The first tier emphasizes the use of empirically-validated instructional strategies and embedded formative assessment techniques to ensure that all students are meeting benchmarks. According to Fuchs and Fuchs (2007), this tier begins with the use of a universal screening tool and a minimum of 5 weeks of progress monitoring to determine those students who are struggling.

For students who have academic difficulties, intervention at the second tier should consist of a standard treatment protocol accompanied by frequent progress monitoring (e.g., curriculum based measurement) to determine student response. Those students who do not respond to this intervention will progress to the third tier. Identifying these non-responders should be accomplished through the use of dual discrepancy data which consists of data on the rate of improvement as determined by progress monitoring in conjunction with a comparison of the student's final level and benchmark criterion. Once identified as at risk, the use of a multidisciplinary approach to evaluation will provide information concerning how best to facilitate the student's learning. In the third tier, support for students normally involves the use of special education services (Fuchs \& Fuchs, 2007).

The model proposed by Fuchs and Fuchs (2007) is one example of RTI implementation. Throughout the RTI literature there are varying descriptions of RTI and school systems are left to translate these interpretations into a coherent approach that is functional for their educators and their students (Fuchs \& Fuchs, 2008). However, the lack of procedural direction provided in the literature can result in inconsistent interpretations of RTI (Reynolds \& Shaywitz, 2009). In the past 3 years, school districts in Ontario have begun the process of interpreting these models and the tiered approach shared in Education for All (OME, 2005) in an effort to implement RTI (Mattatall, 2011; Pyle, in press).

\section{Ontario's RTI Model}

Education for All (OME, 2005) does not mandate the use of RTI, but it does recommend a tiered approach to intervening with students at risk for later learning difficulties. In the first tier, beginning in kindergarten, teachers are expected to use scientifically validated instructional strategies to ensure high quality programming for all students. This teaching should be accompa- 
nied by embedded assessment techniques to systematically monitor the progress of students and ensure continued growth. Those students who do not meet the expected benchmarks are recommended for the second tier where, in addition to their regular classroom instruction, they would receive more intense intervention.

This tiered model acknowledges that not all students will demonstrate substantial improvement as a result of early intervention because it is most effective in assisting those students who struggle due to environmental factors such as inadequate opportunities to develop the requisite language skills (Vellutino, Scanlon, Small, \& Fanuele, 2006). For students who continue to show little or no improvement, a third tier is provided. At this point, students are referred for psycho-educational assessment and possible special education identification. The information gathered during all tiers of the intervention facilitates the development of individualized plans to support students.

The tiered approach described in Education for All (OME, 2005) embraces much of what is described in the RTI literature. However, this description does not provide clear procedures for school district implementation. The description of RTI put forth by the Ontario Ministry of Education does not define non-response of students in tier two nor does it concretely describe the type of intervention that is appropriate for these students and the provision of this support for non-identified students. Further debate about RTI stems from the difference between how a learning disability (LD) is defined by jurisdictions such as Ontario and how it may be defined within the RTI framework. The current definition in Ontario describes LD as a discrepancy between intellectual ability and achievement, while the RTI model classifies students as LD when there is a failure to respond to intervention (Kavale, Holdnack, \& Mostert, 2006). These issues are not unique to Ontario; they have been raised in the research on the viability of using RTI to identify students at risk for later learning difficulties (e.g., Reynolds \& Shaywitz, 2009).

\section{Ontario's Current Special Education Model and its Relationship to RTI}

One of the stated purposes of RTI is to determine entitlement to special education services when a student has not responded to intervention (Danielson, Doolittle, \& Bradley, 2007). In Ontario, the currently mandated process for identifying students with learning disabilities involves in-school team meetings, formal identification of the student's exceptionality, and the development of Individualized Education Plans (IEP). The funding model is based on identifications verified through psycho-educational testing (Hutchinson \& Martin, 2012; OME, 2001).

In areas of the United States where RTI has been fully implemented, it either replaces or is mandated as an alternative to the IEP process that exists in Ontario. However, Ontario school districts have begun to implement RTI while still maintaining the IEP process as the only recognized way of providing intervention to students with exceptionalities (OME, 2001). In Ontario, the data from RTI progress monitoring can be used to facilitate the development of an intervention plan, but it cannot be used to identify a student with an LD. According to Ontario's current special education model, a student is identified with an LD when there is "...a significant discrepancy between academic achievement and assessed intellectual ability” (OME, 2001, A19). Determining the existence of a discrepancy involves testing procedures that require waiting "until Grade three or four when a 2-year discrepancy between academic performance and grade level can emerge" (McNamara, Scissons, \& Dahleu, 2005, p. 81). This type of psycho-educational assessment is then used to identify students and results in the development of a formal IEP (Hutchinson, 2010). During IEP development, consideration is given to the additional supports required by these students including intervention procedures. The discrepancy requirements inte- 
gral to the required testing run counter to one of the central purposes of RTI: to intervene early when students are at risk for later learning difficulties because the provision of support in Ontario is currently contingent on a formal identification which is determined by psychoeducational assessment. This type of contingent support leads to potential barriers to the provision of tier two interventions. In tier two, students have yet to be formally identified. However, a student's placement in tier two results from data that demonstrate that he or she is at risk for later learning difficulties. Despite this data, the provision of intervention for these students is not addressed in the current model. The special education model described above differs from the procedures described in conceptions of RTI, resulting in a lack of alignment and increasing the challenges involved in implementing RTI in Ontario.

\section{Supporting Teachers in the Implementation of New Initiatives}

Implementing new initiatives such as RTI into a school system is a complex process made more complicated by the lack of coherence between existing practices in Ontario and the requirements of the new model. Coherence, for the purposes of this research, is defined as how well the recently developed initiatives enmesh with existing practices and facilitate the accomplishment of a common goal (Madda, Halverson, \& Gomez, 2007). In the case of RTI, a lack of coherence can inhibit the transformative power and limit the sustainability of the model (Kozleski \& Huber, 2010). The extant research has described several factors that can present challenges to the implementation of RTI.

In Fuchs and Deshler's (2007) exploration of the unresolved issues encountered when implementing an RTI model, the authors describe the range of new skills required by teachers and the resulting need for schools and school boards to provide considerable and sustained professional development programs to facilitate the learning of these new skills. There are a plethora of differing perspectives regarding the types of support that are necessary to facilitate the successful implementation of new initiatives such as RTI (Denton et al., 2003; Kratochwill, Volpiansky, Clements, \& Ball, 2007). For example, Fuchs and Deshler described the importance of providing teachers with the time to think about and discuss how best to integrate their learning into their classroom practice.

This perspective is complemented by Guskey's (2002) goals of professional development. $\mathrm{He}$, too, described the time that is needed to enact true change in teacher practice. However, Guskey took his model one step further stating that an instructional approach, materials, curriculum, or teaching procedures must result in a change in student learning outcomes. Guskey posited that a change in teachers' attitudes and beliefs is a result of the changes they see in student learning and not a direct result of the professional development itself. To alter teacher practice, student learning, and teacher attitudes and beliefs, the commonly used one-shot workshop and conference attendance is insufficient because this type of professional development does not fundamentally alter teachers' knowledge and practice (Boyle, Lamprianou, \& Boyle, 2005). For this reason, it is important to consider characteristics that can contribute to the successful implementation of new programs.

Guskey (2003) examined the lists of essential professional development characteristics of 11 organizations including, but not limited to, the American Federation of Teachers, the Educational Research Service, and the U.S. Department of Education. Guskey's examination resulted in six common goals. Of primary concern for this paper is the fifth element in this list: the alignment of professional development with other reform initiatives (Guskey, 2003). A focus on this element is further justified by numerous empirical studies of program implementation that 
describe the importance of the program's coherence with the existing system (e.g., KinnucanWelsch, Rosemary, \& Grogan, 2006; Klingner, Ahwee, Pilonieta, \& Menendez, 2003). The need for this alignment can require substantial alterations at the classroom, school, and system levels.

\section{Challenges to RTI Implementation}

Teachers' perceptions of a new program can have a definite impact on its successful implementation. In their discussion of systemic changes required to implement RTI, Kozleski and Huber (2010) described one of the inhibiting perceptions: the view of RTI as an addition to existing practices. When teachers perceive RTI as an additional task rather than an integral part of an improvement plan and a core element of assessment procedures, the successful implementation of the model is put at risk. Research demonstrates that this situation can result in teachers struggling to give the initiative the necessary focus to ensure its success (Kozleski \& Huber, 2010).

In Ontario, teachers are subject to multiple mandates concerning the identification of students in need. In addition to curriculum documents outlining academic expectations, they often face board-specific initiatives that attempt to better meet these learning outcomes. This is compounded by Ministry initiatives such as the Ontario Focused Intervention Partnership (OFIP), an initiative that focuses on improving student scores in the large-scale assessments that were implemented by the Education Quality and Accountability Office. Further, teachers are bombarded with an ever-growing number of policy documents that emphasize appropriate teaching practices (OME, 2005) and specific procedures for groups of exceptional students (OME, 2001). These issues are not unique to the Ontario context as other provinces also mandate the use of curriculum documents, have multiple ongoing initiatives, and use their provincial testing data to plan professional development designed to improve student results (e.g., Manitoba Education, 2009; Webber, Aitken, Lupart, \& Scott, 2009). The existence of this plethora of initiatives and the incommensurable goals they often represent can make it difficult for teachers to determine which objectives should take primacy (Madda et al., 2007), causing them to revert to previous practices. An unwillingness to focus energy on RTI calls into question the sustainability of the model.

\section{Sustainability}

The extant research into the sustainability of new educational initiatives addresses the need for systemic change, defined by Adelman and Taylor (2007) as involving "modifications that amount to a cultural shift in institutionalized values" (p. 57). The authors argued that to promote the sustainability of an initiative, eliminating a project mentality is necessary, that is, from the view that changes are being made strictly as a result of a particular project and that these changes are applicable only to this implementation. The inclusion of progress monitoring as a central component of RTI may result in a project mentality if it is not accompanied by systemic change to the existing assessment procedures used to determine student support (i.e., providing early intervention for students at risk for later learning difficulties prior to formal identification). To further delve into the requirements specific to RTI implementation an exploration of this body of research follows.

\section{RTI Implementation}

Though in its infancy, there is much discussion in the literature about the implementation of RTI and the elements that must be in place to facilitate its sustainability. Lembke, Garman, 
Deno, and Stecker (2010), in their discussion about one school's implementation of RTI, described the importance of the inclusion of four elements: staff and administrative buy-in, the use of curriculum based measurement (CBM), the inclusion of evidenced-based teaching practices in both classroom practice and interventions, and the collaboration of staff. The need for commitment, consistency, and collaboration has been shown in other empirical studies (e.g., Mahdavi \& Beebe-Frankenberger, 2009). However, these studies were conducted in an American context where changes to the identification procedures have already occurred (Glover \& Diperna, 2007), allowing for early intervention with students who are at risk. There is a danger that, failing the provision of a support structure that provides preventive intervention to younger students, the tiered approach recommended in Education for All (OME, 2005) may not be sustainable.

In summary, the literature suggests that the implementation of RTI requires substantial change to teacher practices; change which may not be coherent with current policies and other initiatives. Thus, the aim of the present paper is to explore the issues presented by the lack of coherence in Ontario's current special education policies and RTI from the perspectives of educators piloting an RTI model. By describing the tensions that arise from listening to teachers' perspectives, areas of implementation that can be improved to enhance the sustainability of RTI are highlighted.

\section{Method}

The study reported here comprised one component of a larger research initiative, piloting an RTI approach to integrative service delivery, carried out by a mid-sized board in southern central Ontario. The larger research initiative sought to empirically test the usefulness of RTI in increasing teacher capacity for providing literacy instruction and increasing the literacy achievement of all students as well as to test the viability of the model in the Ontario context. At the end of the first year, focus group data addressing the enablers and barriers encountered throughout the pilot were gathered from participating teachers. The information shared during these focus groups provides the foundational data for this paper.

The five RTI pilot schools were selected through an independent nomination and review process carried out by the district school board. At each of these elementary schools, all primary classes ( $\mathrm{K}$ to 3 ) participated in the project although not all teachers who participated in the larger project were involved in the focus groups of this study. During this pilot, administrators and teachers (i.e., primary classroom teachers, learning resource teachers, and literacy improvement teachers) worked with board personnel (i.e., special education consultants, school psychologists, child and youth workers, and speech and language pathologists). These partnerships were established to facilitate RTI implementation, including progress monitoring. The implementation was designed incrementally with the focus in the first year of implementation on tier one programming and the integration of progress monitoring in pilot schools. All personnel were required to use CBM for progress monitoring, but in an effort to respect the unique learning environments, schools were encouraged to make other programming decisions based on contextual needs.

\section{Participant Selection}

Participation in the focus groups occurred through self-selection by school staff, although there was some variation in the selection process. At two schools the principal selected one teacher from each grade, from those who expressed an interest, to participate in the focus groups. At two schools individual teachers self-nominated by emailing a research assistant acting as the 
board contact person for the larger RTI pilot. This self-nomination process resulted in some schools not having teachers from all grades volunteer to participate. Therefore, representation from two schools was not consistent across the grade groupings, though each of these schools was represented in at least one focus group. The learning resource teachers for each of the four participating schools attended a separate focus group. One of the five schools involved in the larger research initiative declined to participate in the focus groups.

After teachers were either nominated or indicated their interest in participating, they were invited to the focus group specific to their grade or role. The participant selection process resulted in a total of 18 participants (17 women). These teachers, whose years of teaching experience ranged from 3 to 27 years, had no prior experience with or training in the RTI model prior to the beginning of the pilot.

\section{Focus Group Procedures}

Data were gathered from teachers through five focus groups in the spring of the first year of implementation of RTI. The use of focus groups allowed teachers to share their experiences in a conversational environment. The resulting discussions between participants enhanced the quality of the data as "participants both quer[ied] each other and explain[ed] themselves to each other" (Morgan, 1996, p. 139). As well, these conversations allowed for similarities and differences in perspectives to quickly become evident (Patton, 2002). Each focus group lasted approximately 60 minutes and took place during working hours with release time provided to the teachers involved, ensuring that participation did not interfere with teachers' personal time.

Each focus group consisted of three to five teachers, each from a different school. Although these are small focus groups, the decision was made that teachers working at the same school would not be in focus groups together. Relationship and rank differences can often create an environment where participants are more cautious about what they share (Champion, 2003). The smaller group size also allowed each participant more time to share their personal experiences of RTI implementation (Morgan, 1996). To ensure common ground amongst the participants, teachers from the same grade attended each focus group and all learning resource teachers attended a separate group. This resulted in five focus groups, one group for each grade that participated in the project ( $\mathrm{K}$ to 3 ) and a separate focus group for learning resource teachers.

The five focus groups were facilitated by the author who did not participate in any other aspect of the pilot project. The sole responsibility of this researcher was to moderate the discussions using standardized open-ended questions (e.g., "What impact has RTI had on your students' learning?") and probing questions (e.g., "Could you tell me more about progress monitoring?") to elicit elaboration from the participants. Specifically, participants were asked about (a) supports that were in place to facilitate the implementation of RTI, (b) barriers these teachers faced, and (c) the impact RTI had on their practice.

\section{Analysis of Focus Group Data}

Rigorous analysis of the data began with open coding of each verbatim transcript (Patton, 2002). Each teacher was given a participant code, identifying them and their role within the school. For instance, (1-4) means the statement was made in the Grade 1 focus group, by participant number 4. Teachers' statements were coded line-by-line to 'capture participants' implied and explicit meanings" (Charmaz, 2002, p. 685). Categories were listed in a separate file as they emerged. For example, teachers made statements about the number of assessments they were re- 
quired to complete during the pilot and the time it took to complete them. These two codes were grouped together into the category "assessment procedures." Multiple passes through each transcript were made to ensure that coding accurately reflected the perspectives of the participants. Patton's (2002) method of constant comparison was used to generate codes, categories, and themes. The result of this analysis was five major themes concerning teachers' perceptions of the barriers to their implementation of RTI resulting from its lack of alignment with Ontario's current education system.

\section{Results}

Analysis of the focus group data revealed that one of the central challenges teachers encountered as they implemented RTI was the lack of coherence between the elements of the model and existing instructional practices. This tension was directly related to the differing goals of the progress monitoring tool used in RTI and of existing assessment procedures, the lack of alignment of RTI with other Ministry initiatives (e.g., OFIP), and the lack of integration of data resulting from progress monitoring with existing assessment procedures for determining student support. The results of this study are presented within the five major themes that emerged from the focus group data: overemphasis on assessment, teaching demands, conflicting initiatives, systemic incoherence, and issues of identification and support.

\section{Overemphasis on Assessment: "Asking Teachers to Do More Assessments"}

The pilot project relied on a CBM tool to measure student learning trajectories. This fluency-based tool consisted of letter sound identification in Kindergarten, word identification in Grade 1, and passage reading in grades 2 and 3. The students' scores were measured according to how many letter sounds or words they accurately identified in 1 minute. While this tool has proven to be effective in previous empirical research (e.g., Simmons et al., 2008), this method of evaluation differed from the tools previously used by the teachers. The fluency tool that was used for progress monitoring in the RTI pilot was experienced by the teachers as being at odds with the emphasis on comprehension that was advocated in Ministry professional development and in the board-mandated assessment tool, the Developmental Reading Assessment (DRA):

Focus for us in the last few years has been doing daily running records and the miscue analysis so you know if you're not really looking at those miscues then what is it telling you about where you need to focus your instruction with them? (1-2)

The shift in the emphasis of the assessment tool required that teachers modify their thinking about how students' abilities were measured. In this RTI initiative, the teachers were required not only to complete CBM but also all of the existing assessment procedures. "We do DRA...we use the running record assessment to guide our instruction and that's where I found that asking teachers to do more assessments was a little bit tedious for them because we already had a system in place" (LRT 1). The competing assessment procedures forced teachers to make decisions about which assessments should take priority and many of the participants voiced the belief that their existing tools, those whose use was mandated, were their primary concern: "I might have put that $[\mathrm{CBM}]$ aside because I have to do DRA" (K-3).

This mismatch between existing assessment practices and new requirements resulted in difficulty integrating these initiatives in the classroom. As a result, teachers expressed frustration with the time that it took to complete all of the paperwork involved. But more importantly, the 
teachers described the challenge of designing a program that adequately addressed the needs of the whole class while attending to the students who were at risk and that integrated existing Ministry expectations with the expectations of the RTI model.

\section{Teaching Demands: "Oh No. One More Thing to Do"}

Throughout the focus groups the teachers expressed the feeling that the large amount of time required to complete both existing assessment procedures and new progress monitoring procedures had an impact on their ability to teach their students, as required by the Ontario Ministry of Education curriculum and program documents: "There is one person being spread out so thinly. There is [sic] so many demands and it's always the teacher's responsibility...it's the teacher's job to do, it's always the teacher's job" (K-3). This sentiment was further emphasized by a Grade 2 teacher who questioned how to find time for all the requirements of the RTI model and current assessment practices in Ontario: "More work, how are we going to get it all done? How are we going to get it in? EQAO [Education Quality and Accountability Office testing], DRA, and all these strands...I was just feeling like, oh no, one more thing to do" (2-3). The sheer quantity of assessments required of teachers during the pilot project affected their ability to use what they were learning from these assessments in their teaching. Teachers' believed the RTI process was inhibiting their ability to focus on the interventions it showed their students required.

The main issue for many of these teachers was that the combination of existing assessment procedures and the added progress monitoring came at the expense of their students' learning. This sentiment was especially evident when discussing the type of support they felt at risk learners required but were not receiving. Throughout the focus groups, teachers continually questioned what this intervention should entail: "When we get that [non-response data] where do we go? What are some strategies? What are we going to do to help that child improve?" (2-2). These types of questions were posed by many teachers throughout the focus groups who were struggling to determine the next steps for their students who were at risk: "What strategies do you implement based on the information you've gotten from that probe?" (3-1). In the absence of tier two intervention, which was not introduced in the first year of this pilot, teachers were missing a key element that they yearned for: instructional strategies that would improve the learning of students who were identified as at risk by the CBM. "It always falls back on the classroom teacher...but response to intervention means response to intervention like intervene because I've done all I can" (2-1).

Further challenges also emerged when teachers discussed their ability to program effectively for all of the students in their classrooms. The result was that teachers felt they could not provide the types of learning experiences necessary for their students but instead had to design classroom instruction in a manner that allowed the time to focus on the assessments:

It's taken away some time from my time to work with the children on a more individual or small group basis because I've had to fit it in...the rest of the class has to be doing something that they can be independent at. (1-1)

Lack of alignment between existing assessment procedures and progress monitoring specific to RTI made it difficult for teachers to use progress monitoring data to influence instruction and improve students' learning. For the participating teachers, this overemphasis on assessment resulted in feeling that RTI was an additional task that did not have the intended positive impact on their students' learning. Instead, RTI negatively impacted their practice. This sentiment was further compounded by other, ongoing, initiatives that required teachers' time and attention. 


\section{Conflicting Initiatives: "Feeling Very Overwhelmed"}

Many teachers in Ontario are currently working to implement several Ministry and board imposed initiatives including the OFIP. As a result, the teachers in this pilot encountered challenges as they attempted to continue with these existing initiatives while also introducing RTI:

I think the other issue we have at our school too is that we're an OFIP school and we've got the Ministry coming in at regular intervals so we've got a lot on our plate and so to try and sort of separate out all this stuff, the teachers are feeling very overwhelmed. (LRT 3)

This sentiment was confirmed by many of the teachers in this pilot as is reflected by the words of a Grade 1 teacher, "It's challenging so adding something else was just unreasonable" (1-2). This challenge resulted in discussions concerning the conflicting information they were receiving about what skills they should be emphasizing with students: "[O]ur main focus...has been on comprehension strategies and then we felt this year, when RTI came in, it was on fluency and decoding" (3-3). In the face of the conflicting demands, the teachers in this pilot were having difficulty focusing on how they should be using their instructional time: "I feel like I'm neglecting a lot of kids just because they're more fluent readers but they still have areas that they need to work on and they're kind of getting the short end of the stick" (1-2). The result is a need to streamline and prioritize both the assessment strategies and instructional goals. However, streamlining in this manner will not remedy the system-wide alignment issues that are also present when one considers RTI in the context of Ontario's current special education model.

\section{Systemic Incoherence: "Connectivity is Actually Huge"}

The alignment of existing Ministry initiatives and the RTI model is a small piece of the complex negotiation required to implement RTI into a system that is not designed to function in this manner. Teachers recognized the limitations to RTI within the current special education framework and discussed the challenges of implementing a model that was designed for another educational system: "It's coming from another system, was it an American sort of kind of birth? I think it's really important honestly...making those kinds of matches for people who are used to a certain system" (LRT 3). As a result of the amendments to the Individuals with Disabilities Education Act, the US law ensuring special education services for students with special needs, RTI is recognized in many states as a method for determining a student's qualification for special education services (Lembke et al., 2010). In Ontario, this systemic shift has not occurred.

In this pilot, the lack of alignment that emerged as this foreign model was imposed on their local schools resulted in teachers expressing concern that the challenges involved in translating RTI into a new and unprepared system could create an environment where teachers were reluctant to make the changes necessary to implement the model successfully:

Connectivity is actually huge because what happens then is when you go in to a system and you say 'well everything that we do here now I want you to change that' and what that actually does, for me personally and for a number of other colleagues too, it creates aggravation right off the bat. (LRT 3)

Teacher buy-in plays a central role in the successful implementation of RTI (Lembke et al., 2010). The negative emotions expressed by this teacher, and echoed by other focus group participants, will certainly impact the viability and sustainability of the model: "I think the board took a small approach to one end of it, but I don't have a lot of hope that they're ever going to get to full implementation of RTI" (1-1). Teachers' struggles to buy into RTI are further com- 
pounded by the need to ensure that the current special education identification and support model can make productive use of the data that is provided by the progress monitoring of students who are at risk for later learning difficulties.

\section{Issues of Identification and Support: "Legally, Because of Their IEPs"}

RTI advocates the use of intervention as a step in the identification of students who are at risk. In this model, students who are not progressing at the expected rate should receive intervention to help them make the necessary gains. However, what teachers expressed during the focus groups was that unless all of this intervention could be put in place by classroom teachers, which many suggested was not possible given limited time availability, then there was no support available to these students: "They're supposed to be withdrawn and there's no staff to do that. Our LRTs are already taxed to the max" (1-1). This perspective was shared by the learning resource teachers who described this lack of support as a direct result of the legal obligations imposed when students have a formal identification and an IEP has been developed: "I have 11 LD for two rooms alone so when you have those students you really need to be providing, legally as part of their documentation, their IEPs, you need to be providing additional support to them" (LRT 1). As a result of these obligations, many of the learning resource teachers described the difficult decisions they had to make about who to support. Central to these decisions was the reality that they could not ignore their legal accountability and thus did not have the time or resources to support students who were not formally identified using Ontario's current special education model: "I don't have the time in my day to service all the kids so there's a fine line. Where do you sort of cut your supports?" (LRT 1).

The special education model currently used in Ontario does not acknowledge the data provided by RTI when identifying students and determining support. While Education for All (OME, 2005) does advocate the use of a tiered model based on RTI research, it still recommends testing for all students who require an identification and support to reach academic expectations. The reality expressed by the teachers participating in this pilot was that the current requirement to have students who are at risk undergo psycho-educational assessment prior to receiving additional support inhibits the resource teachers' abilities to intervene with non-identified students:

\footnotetext{
It just seems like there's not enough. The resource people come in and you're bringing a kid to a meeting and you've got the psych assessment people there and it's like 'well you know what? I want you to do something else with this student because there's a 2-year waiting list.' (2-3)
}

The inability for teachers to use the data from progress monitoring to gain support for their students makes the tier two intervention advocated as an essential element of RTI unfeasible. According to these teachers, this a direct result of the continuing need to have all students who are at risk tested prior to their receiving any support.

\section{Discussion}

RTI advocates early intervention as a key step in the process of identification. In this pilot, both the incremental implementation of RTI and the lack of coherence between RTI and the current special education system acted as barriers to the successful implementation of tier two intervention and, as a result, the successful implementation of RTI. These barriers were revealed at both the classroom and system levels. 


\section{Incoherence at the Classroom Level}

At the classroom level, the greatest challenge resulted from the introduction of progress monitoring. The teachers felt an excessive amount of time was devoted to testing student learning rather than to the learning itself. In this pilot, RTI was introduced incrementally with the focus of the first year on tier one programming including the introduction of progress monitoring. However, RTI does not lend itself to partial implementation. This incremental implementation resulted in teacher frustration at the focus on assessment rather than intervention.

The teachers in this pilot were driven by a desire to improve student learning. The perception shared was that progress monitoring did not provide the opportunity for the intervention that their students needed. The improvement in student learning outcomes described by Guskey (2002) as essential to a change in teachers' practice and beliefs was not apparent to the teachers in this pilot because there were no interventions aligned with the CBM assessments. Future implementations of RTI should consider the essential role that intervention and improved student learning play in teacher buy-in. Further, the RTI model so closely integrates assessment and intervention that implementation of one without the other can inherently lead to difficulties and perceptions of a lack of coherence with the existing model. The incremental implementation undertaken in this pilot did not provide the opportunity for the intervention necessary to improve student learning and is not recommended for future implementations. Instead, future research should explore how best to introduce tier one progress monitoring and tier two intervention concurrently.

The incremental implementation was not the only barrier to the integration of tier two intervention. Teacher confusion concerning instructional focus also impeded the implementation. One of the central practices that teachers were required to introduce was progress monitoring using CBM, a fluency-based assessment tool. This resulted in a shift from comprehension-focused instruction to an emphasis on fluency instruction. The teachers in this pilot perceived these to be discrete, perhaps even competing, skills with fluency focusing on decoding and comprehension focusing on extracting the meaning from a text. Research has demonstrated that fluency assessment data are strongly correlated with comprehension ability and it is widely theorized that fluency increases a student's capacity for comprehension (e.g., Wise et al., 2010). The introduction of fluency as part of RTI and the complete separation of this initiative from the existing drive to increase comprehension are problematic. Especially considering their goals are the same: to improve students' reading abilities.

The results of this study suggest that to foster a holistic perspective on reading development, professional development should be designed to communicate the interrelated nature of differing reading skills (L'Allier \& Elish-Piper, 2007). In the context of RTI, this means providing professional development that addresses the interconnectedness of fluency and comprehension and how these skills can be taught in a cohesive manner. Administrative personnel working on separate but interrelated initiatives (e.g., the OFIP comprehension-driven initiative and RTI implementation) must collaborate to ensure that the information is communicated as complementary, to avoid teachers perceiving that the initiatives are competing (Putman, Smith, \& Cassady, 2009).

Accompanying the assimilation of information that is required for teachers, there is a need for further information about the instructional strategies that should be provided during tier two interventions. Future research should explore the types of instruction that benefit students who are in tier two. This research should consider not only the types of skills that would benefit these students but also the intensity required for improvement. 


\section{Incoherence at the System Level}

At the system level, there are two parallel agendas enacted in Ontario. Education for All (OME, 2005) advocates the use of a tiered approach based on RTI research. In this model, regular progress monitoring is used to ensure responsive intervention for students at risk for later learning difficulties. However, the use of RTI is not supported by the mandated special education model that maintains that student identification and support must be determined through psychoeducational assessment. In the pilot schools, only students who had an identification resulting from this testing were provided with additional support. The lack of alignment between these models emerged throughout the data gathered from the teachers in this study as they described the unresolved issues of identification and support.

The tiered approach advocates that empirically-validated instruction, regular monitoring of student learning, and the provision of additional support for students at risk for later learning difficulties should begin in kindergarten. However, the teachers in this pilot project clearly communicated their struggles with providing intervention to their youngest students. These students must remain on a waiting list for testing before the necessary support can be provided resulting in teacher and student frustration as they wait for the failure that is necessary to the provision of much needed support.

For RTI to be successfully implemented in Ontario, or any system where psychoeducational testing is the gateway to additional support, systemic change is needed. If the continued use of psycho-educational testing is necessary, a positive decision according to many researchers (e.g., Fuchs \& Fuchs, 2007), then the support acquisition procedures must be amended. This statement is not intended as a promotion of the use of RTI progress monitoring data to identify students with a learning disability. Considering the challenges that are described in the extant research concerning this process (e.g., Reynolds and Shaywitz, 2009), this argument is beyond the scope of this study. Rather the intention of this recommendation is that intervention support should not come solely as the result of a formal identification of an LD but rather should also result from progress monitoring data demonstrating a lack of expected progress. For this to occur, a concrete definition of non-response to intervention that can be used to determine support for younger students is needed. This definition should be accompanied by procedural directions concerning the intervention that students who are not responding would receive.

Once this definition is established, intervention can be more readily provided to younger students who are struggling. Even with this change, what remains unclear is who will provide this intervention? Future research should explore the roles of personnel in an RTI model. More specifically, in exemplary cases of RTI implementation, what successful tier two intervention models are used, who is responsible for this instruction, and what training has been provided to these educators?

Ontario's decision to include RTI in Ministry documentation demonstrates the acceptance of this model as a positive approach to working with students at risk for later learning difficulties. However, for RTI to become an integral part of the special education model, systemic change is needed. If there is no change to both the implementation procedures and the identification and support structures, classroom level changes made by teachers will continue to result in a lack of support for students who are struggling. The result will be response to intervention minus the intervention, and this is neither desirable nor sustainable. 


\section{References}

Adelman, H. S., \& Taylor, L. (2007). Systemic change for school improvement. Journal of Educational and Psychological Consultation, 17(1), 55-77. doi:10.1080/10474410709336590

Boyle, B., Lamprianou, I., \& Boyle, T. (2005). A longitudinal study of teacher change: What makes professional development effective? Report of the second year of the study. School Effectiveness and School Improvement, 16(1), 1-27. doi:10.1080/09243450500114819

Champion, R. (2003). Frank discussion in focus groups can yield useful data. National Staff Development Council, 24(4), 61-62. Retrieved from http://www.learningforward.org/index.cfm

Charmaz, K. (2002). Qualitative interviewing and grounded theory analysis. In J. F. Gubrium \& J. A. Holstein (Eds.), Handbook of interview research: Context and method (pp. 675-694). Thousand Oaks, CA: Sage.

Danielson, L., Doolittle, J., \& Bradley, R. (2007). Professional development, capacity building, and research needs: Critical issues for response to intervention implementation. School Psychology Review, 36, 632-637. Retrieved http://www.nasponline.org/publications/spr/index-list.aspx

Denton, C. A., Vaughn, S., \& Fletcher, J. M. (2003). Bringing research-based practice in reading intervention to scale. Learning Disabilities Research \& Practice, 18, 201-211. doi:10.1111/1540-5826.00075

Feiker Hollenbeck, A. (2007). From IDEA to implementation: A discussion of foundational and future responsiveness-to-intervention research. Learning Disability Research \& Practice, 22, 137-146. doi: 10.1111/j.1540-5826.2007.00238.x

Fuchs, D., \& Deshler, D. D. (2007). What we need to know about responsiveness to intervention (and shouldn't be afraid to ask). Learning Disabilities Research \& Practice, 22, 129-136. doi: 10.1111/j.1540-5826.2007.00237.x

Fuchs, D., \& Fuchs, L. (2008). Implementing RTI: Response-to-intervention is an ambitious and complex process that requires administrators choose the right model. District Administration, 44(11), 73-76. Retrieved from http://www.districtadministration.com/article/implementing-rti

Fuchs, L. S., \& Fuchs, D. (2007, May/June). A model for implementing responsiveness to intervention. Teaching Exceptional Children, 14-20.

Glover, T. A., \& Diperna, J. C. (2007). Service delivery for response to intervention: Core components and directions for future research. School Psychology Review, 36, 526-540. Retrieved from http://www .nasponline.org/publications/spr/index-list.aspx

Greenfield, R., Rinaldi, C., Proctor, C. P., \& Cardarelli, A. (2010). Teachers' perceptions of a response to intervention (RTI) reform effort in an urban elementary school: A consensual qualitative analysis. Journal of Disability and Policy Studies, 21(1), 41-63. doi:10.1177/1044207310365499

Guskey, T. R. (2002). Professional development and teacher change. Teachers and Teaching: Theory and Practice, 8, 381-391. doi:10.1080/135406002100000512

Guskey, T. R. (2003, June). What makes professional development effective? Phi Delta Kappan, 748-750. Retrieved from http://www.kappanmagazine.org/

Hutchinson, N. L. (2010). Inclusion of exceptional learners in Canadian schools. Toronto, ON: Pearson Education Canada.

Hutchinson, N. L., \& Martin, A. K. (2012). Inclusive classrooms in Ontario schools. Toronto, ON: Pearson Education Canada.

Kavale, K. A., Holdnack, J. A., \& Mostert, M. P. (2006). Responsiveness to intervention and the identification of specific learning disability: A critique and alternative proposal. Learning Disability Quarterly, 29, 113-127. doi:10.2307/30035539

Kinnucan-Welsch, K., Rosemary, C. A., \& Grogan, P. R. (2006). Accountability by design in literacy professional development. The Reading Teacher, 59, 426-435. doi:10.1598/RT.59.5.2

Klingner, J. K., Ahwee, S., Pilonieta, P., \& Menendez, R. (2003). Barriers and facilitators in scaling up research-based practices. Exceptional Children, 69, 411-429. Retrieved from http://cec.metapress.com /content/122146

Kozleski, E. B., \& Huber, J. J. (2010). Systemic change for RTI: Key shifts for practice. Theory Into Practice, 49, 258-264. doi:10.1080/00405841.2010.510696 
Kratochwill, T. R., Volpiansky, P., Clements, M., \& Ball, C. (2007). Professional development in implementing and sustaining prevention models: Implications for response to intervention. School Psychology Review, 36, 618-631. Retrieved from http://www.nasponline.org/publications/spr/indexlist.aspx.

L'Allier, S. K., \& Elish-Piper, L. (2007). Ten best practices for professional development in reading. Illinois Reading Council Journal, 35(1), 22-27. Retrieved from http://www.illinoisreadingcouncil.org /publicationsservices/ircjournal.html

Lembke, E. S., Garman, C., Deno, S. L., \& Stecker, P. M. (2010). One elementary school's implementation of response to intervention (RTI). Reading \& Writing Quarterly, 26, 361-373. doi:10.1080 /10573569.2010.500266

Madda, C. L., Halverson, R. R., \& Gomez, L. M. (2007). Exploring coherence as an organizational resource for carrying out reform initiatives. Teachers College Record, 109, 1957-1979. Retrieved from http:// www.tcrecord.org/

Mahdavi, J. N., \& Beebe-Frankenberger, M. E. (2009, Nov/Dec). Pioneering RTI systems that work. Teaching Exceptional Children, 64-72.

Manitoba Education. (2009). Interpreting and using results from provincial tests and assessments: A support document for teachers, administrators, and consultants. Winnipeg, MB: Manitoba Text Book Bureau. Retrieved from http://www.edu.gov.mb.ca/k12/assess/support/results/interpreting.pdf

Mattatall, C. A. (2011). A study of how one Ontario school board used peer assisted learning strategies and data-informed decision-making to address reading failure at Grade 1. (Unpublished doctoral dissertation). Queen's University, Kingston, ON, Canada.

McNamara, J. K., Scissons, M., \& Dahleu, J. (2005). A longitudinal study of early identification markers for children at-risk for reading disabilities: The Matthew effect and the challenge of over-identification. Reading Improvement, 42(2), 80-97. Retrieved from EBSCOhost.

Morgan, D. L. (1996). Focus groups. Annual Review of Sociology, 22, 129-152. doi:10.1146 /annurev.soc.22.1.129

Ontario Ministry of Education. (2001). Special education: A guide for educators. Toronto, ON: Queen's Printer for Ontario. Retrieved from http:/www.edu.gov.on.ca/eng/general/elemsec/speced/guide /specedhandbooke.pdf

Ontario Ministry of Education. (2005). Education for all. The report of the expert panel on literacy and numeracy instruction for students with special education needs, kindergarten to grade 6. Toronto, ON: Queen's Printer for Ontario. Retrieved from http://www.edu.gov.on.ca/eng/document/reports/speced /panel/speced.pdf

Patton, M. Q. (2002). Qualitative research \& evaluation methods. Thousand Oaks, CA: Sage.

Putman, S. M., Smith, L. L., \& Cassady, J. C. (2009). Promoting change through professional development: The place of teacher intentionality in reading instruction. Literacy Research and Instruction, 48, $207-$ 220. doi:10.1080/19388070802251988

Pyle, A. (in press). "Just listen to us." The role of teacher empowerment in the implementation of RTI. Alberta Journal of Educational Research, 57(3).

Reynolds, C. R., \& Shaywitz, S. E. (2009). Response to intervention: Ready or not? Or, from wait-to-fail to watch-them-fail. American Psychological Association, 24(2), 130-145. doi:10.1037/a016158

Simmons, D. C., Coyne, M. D., Kwok, O., McDonagh, S., Harn, B. A., \& Kame'enui, E. J. (2008). Indexing response to intervention: A longitudinal study of reading risk from kindergarten through third grade. Journal of Learning Disabilities, 41, 158-173. doi:10.1177/0022219407313587

Vellutino, F. R., Scanlon, D. M., Small, S., \& Fanuele, D. P. (2006). Response to intervention as a vehicle for distinguishing between children with and without reading disabilities: Evidence for the role of kindergarten and first grade interventions. Journal of Learning Disabilities, 29, 157-169. doi:10.1177/00222194060390020401

Webber, C. F., Aitken, N., Lupart, J., \& Scott, S. (2009). The Alberta student assessment study: Final report. Edmonton, AB: Learning Resources Centre. Retrieved from http://education.alberta.ca/media /1165612/albertaassessmentstudyfinalreport.pdf 
Wise, J. C., Sevcik, R. A., Morris, R. D., Lovett, M. W., Wolf, M., Kuhn, M.,...Schwanenflugel, P. (2010). The relationship between different measures of oral reading fluency and reading comprehension in secondgrade students who evidence different oral reading fluency difficulties. Language, Speech \& Hearing Services in Schools, 41, 340-348. doi:10.1044/0161-1461(2009/08-0093)

\section{Author's Note}

Correspondence concerning this article should be addressed to Angela Pyle, Queen's University, Faculty of Education, Duncan McArthur Hall, Room 106, Kingston, ON, K7M 5R7.

Email: angela.pyle@queensu.ca 